\title{
A Bíblia na catequese
}

\author{
The Bible in the catechesis
}

Fabiana de Sousa

\section{Resumo}

O Concílio do Vaticano II (1963-1965) não tratou de forma explícita o tema da catequese, mas teve impacto determinante no campo catequético, sobretudo quando deu destaque à Bíblia, à Igreja e ao ser humano. O Concílio do Vaticano II permite evidenciar que a Bíblia e a catequese estão conexas entre si, por estarem em profunda relação com a Palavra de Deus. A Bíblia é a Palavra de Deus revelada e posta por escrito no decorrer da história da salvação. Já a catequese (do grego katá-ekhein), que significa "ressoar", recebeu da Igreja o sentido de ressoar a Palavra de Deus nos dias de hoje. Para tanto, faz-se necessário esclarecer o que é a Palavra de Deus propriamente dita e qual a sua relação com a Revelação e com a Sagrada Escritura. Também será preciso enfocar a dimensão da catequese, destacando sua relação com a Palavra de Deus, seu ministério de serviço desta Palavra, a sua atuação no processo de educação da fé e sua importância como primeiro anúncio. Contudo, devem-se considerar alguns fatores limitantes para que a Bíblia seja o livro por excelência da catequese. É necessário ainda desenvolver alguns critérios metodológicos, com a intenção de favorecer o uso da Bíblia na catequese. A leitura da Bíblia na catequese precisa ser capaz de aprofundar o sentido da própria vida.

Palavras-chave: Bíblia, catequese, Vaticano II.

\section{Abstract}

The Second Vatican Council (1963-1965) did not address explicitly the topic of catechesis, but it had major impact on the catechetical field. Especially considering it emphasized the Bible, the Church and the human being. The 
Second Vatican Council gives evidence that the Bible and the Catechesis are related one each other, being in deep connection with the Word of God. The Bible is the revealed Word of God in writing in the course of the salvation history. In the other hand, the Catechesis (Greek katá-ekhein), which means "to echo", received from the Church the meaning of echoing the Word of God nowadays. Therefore, it is necessary to clarify what the Word of God is, what its connection with the Revelation and the Sacred Scripture is. Also another dimension of catechesis must be focused: highlighting its relationship with the Word of God, ministry of service of this Word, its performance in the process of education in the faith and its importance as the first announcement. However, one should consider some limiting factors so that the Bible to be the book of Catechesis par excellence. It is also necessary to develop some methodological criteria, aiming to promote the use of the Bible in catechesis. Reading the Bible in catechesis needs to able deepening the meaning of life.

Keywords: Bible, catechesis, Second Vatican.

\section{Introdução}

O Concílio Vaticano II (1963-1965) trouxe, sem dúvida, um novo modo de compreender a catequese. ${ }^{1}$ Sua orientação marcou o fim de um longo período caracterizado pelo uso preponderante dos catecismos e memorização de fórmulas catequéticas. A proposta do Concílio foi reconduzir a catequese à primeira fonte: a Palavra de Deus, redescoberta principalmente na Bíblia. No mais, quis repensar a catequese na perspectiva de educação da fé, como atitude existencial e global da pessoa. Quis recolocar a catequese num projeto de Igreja mais diaconal e comunial.

No período pós-conciliar, essa perspectiva se tornou cenário para o desenvolvimento de novas orientações. Nasceu um novo modelo de catequese. A catequese pós-conciliar ganhou uma nova face, com traços característicos, que dominaram ao longo das últimas décadas a reflexão catequética. Colocou-se em relevo o primado da evangelização, a emergência da Bíblia, a dimensão antropológica, a sensibilidade sociopolítica, a prioridade para os adultos, a centralidade da comunidade, a valorização da mídia e das linguagens não verbais etc.

\footnotetext{
${ }^{1}$ ALBERICH, Emílio. A catequese no contexto do Concílio Vaticano II e o pós-Concílio, p. 15-26.
} 
Contudo, a catequese pós-conciliar atua num mundo permeado de novas exigências e em busca de respostas adequadas aos novos desafios, presentes numa sociedade marcada por mudanças significativas. ${ }^{2}$

Em vista do Concílio Vaticano II, esta pesquisa busca evidenciar que a Bíblia e a catequese estão conexas entre si, por estarem em profunda relação com a Palavra de Deus.

\section{A Palavra de Deus e a Bíblia}

Desde o início da história da salvação, a comunicação entre Deus e seu povo se dá pela Revelação de sua Palavra. A Palavra de Deus é dinâmica, atua na história, permitindo ao homem participar de seu mistério em vista da salvação de toda a humanidade.

A Bíblia é estimada como Palavra de Deus, pois seu conjunto de livros é admitido como inspirado pelo próprio Deus e consignado por escrito de uma vez para sempre. Desse modo, comunica imutavelmente a Palavra do próprio Deus e faz ressoar, através das palavras dos profetas e apóstolos, a voz do Espírito de Deus.

Contudo, a Bíblia não é a única fonte da Palavra de Deus. Constitui, ao lado da Sagrada Tradição, um único depósito sagrado desta Palavra confiado à Igreja. Com efeito, a Bíblia é a Palavra de Deus enquanto redigida sob a moção do Espírito Santo. "A Sagrada Tradição, por sua vez, transmite integramente aos sucessores dos apóstolos a Palavra de Deus, para que, sob a luz do Espírito Santo, fielmente conservem, exponham e difundam a Palavra de Deus. Não é apenas através da Bíblia que nasce a certeza da Igreja sobre tudo que foi revelado. Sendo assim, Bíblia e Tradição devem ser igualmente veneradas." ${ }^{3}$

\subsection{A Palavra de Deus}

No ambiente bíblico, o termo "palavra" não significa apenas um meio de comunicação entre homens. Não é somente resultado de uma ideia. É princípio ativo e eficaz que participa do dinamismo da pessoa que a pronuncia. De certo modo, subsiste por si mesma (Pr 18,4; Dt 32,1-2). Daí a eficácia e o valor

${ }^{2}$ ALBERICH, Emílio. Catequese evangelizadora; manual de catequética fundamental. São Paulo: Salesiana, 2007. p. 36.

${ }^{3}$ Dei Verbum, n. 9, in: COMPÊNDIO DO VATICANO II. Constituições. Decretos. Declarações. Petrópolis: Vozes, 1986. 
da palavra pronunciada na hora de ajuizar a vida do homem $(\operatorname{Pr} 10,20-21$; Eclo 5,13-14).

No contexto religioso e cultural, a palavra proferida por Deus adquire um protagonismo singular. Ela é o meio pelo qual Deus entra em comunicação com o homem. Primeiramente, como palavra criadora e conservadora, ou seja, Deus fez e continua a fazer o que quer (Gn 1,3; Is 40,8-9). Em segundo lugar, como realidade reveladora do sentido dos acontecimentos e das coisas (Ex 3,13-15; Is 2,3-5), enquanto lei e regra de vida (Ex 34,28) e anúncio e promessa de um porvir glorioso (Js 1,1-15; Is 40,1-2).

O Antigo Testamento inicia a personificação da palavra divina (Is 55,11; S1 107,20). Esse processo culmina no Novo Testamento, quando Deus se revela em seu Filho Jesus Cristo como palavra substancial, que se torna homem entre os homens (Jo 1,1-14; 1Jo 1,1-3). A partir deste evento fundamental, compreende-se melhor que a Palavra de Deus em Cristo é uma realidade criadora (Hb 1,3), reveladora do mistério de Deus (Mt 13,19-23), ressuscitadora e portadora de vida e salvação (Jo 5,24-28; Mc 5,41), poderosa, penetrante e eficaz (1Ts 2,13; $2 \mathrm{Tm} 2,9-13$; $\mathrm{Hb} 4,12$ ).

\subsection{A Palavra de Deus e a Revelação}

A palavra é a principal forma de comunicação humana. Mas o homem também pode comunicar-se através de gestos ou acontecimentos. Deus, para comunicar-se com os homens, utilizou estas duas linguagens que se completam. ${ }^{4}$ Deus se revela e se comunica com os homens na linguagem de homens:

Aprouve a Deus, em sua bondade e sabedoria, revelar-se a si mesmo e tornar conhecido o mistério de sua vontade [...]. Este plano de Revelação se concretiza através de acontecimentos e palavras intimamente conexos entre si, de forma que as obras realizadas por Deus na história da salvação manifestam e corroboram os ensinamentos e as realidades significadas pelas palavras. [...] As palavras de Deus com efeito, expressas por línguas humanas, tornaram-se ìntimamente semelhantes à linguagem humana, como outrora o Verbo do eterno Pai se assemelhou aos homens tomando a carne da fraqueza humana. ${ }^{5}$

${ }^{4}$ CONFERÊNCIA NACIONAL DOS BISPOS DO BRASIL. Catequese renovada. São Paulo: Paulinas, 1986. n. 34.

${ }^{5}$ Dei Verbum, n. 2;13. 
De fato, Deus entra na história por sua palavra. Agora o homem pode experimentar quem é Deus. Esta autocomunicação resulta no conhecimento de Deus, para o qual o homem se abre em virtude da Revelação. O homem necessita, para sua salvação, voltar-se a Deus e à sua palavra: "Enviou-lhes Deus a sua palavra e os curou" (S1 97,20). ${ }^{6}$

Ao Deus que se revela, o homem deve entregar-se livremente e assentir à Revelação feita por Ele. Esta manifesta os decretos eternos da vontade divina com relação à salvação dos homens. No entanto, para essa salvação Ele não comunica apenas alguma verdade ou alguma lei, mas comunica a si mesmo, sua presença e seu amor. Deus, ao revelar-se, procura guiar a humanidade, orientá-la e aproximá-la de Si. Em contrapartida, "ao Deus que se revela, deve-se a obediência da fé". ${ }^{7}$

A Palavra de Deus revelada interpreta e ilumina a existência humana à luz do projeto salvador de Deus. Por meio da sua palavra, Deus falou de muitas maneiras a nossos pais na fé. Todavia, de modo perfeito e definitivo revelou-se plenamente em Jesus Cristo (Hb 1,1-2): "Nele, Deus não se limita a manifestar algo de seu amor. Deus se dá a si mesmo. Jesus é a encarnação, na natureza humana, do verbo. É a própria 'Palavra de Deus' feita carne (Jo 1,14)" ${ }^{8}$ É a suprema manifestação de Deus ao homem e a suprema Revelação do homem ao homem. ${ }^{9}$ Cristo é, de fato, o logos, a palavra do Pai (Jo 1), a sabedoria de Deus (1Cor 1,24), a imagem do Deus invisível $(\mathrm{Cl} 1,15)$, resplendor de sua glória e expressão de sua substância $(\mathrm{Hb}$ 1,3).

\subsection{A Palavra de Deus e a Sagrada Escritura}

“A Sagrada Escritura é a Palavra de Deus enquanto é redigida sob a moção do Espírito Santo." ${ }^{10}$ De acordo com testemunhos dos textos bíblicos, a palavra falada por Deus foi exarada por escrito a fim de lembrar ao povo sem cessar esta palavra (Dt 31,9-13).

No centro das Sagradas Escrituras estão os evangelhos, que apresentam Jesus, o Cristo. Sendo ele plenitude máxima da Revelação, ordenou aos

${ }^{6}$ EICHER, Peter. Dicionário de conceitos fundamentais de teologia. São Paulo: Paulus, 1993, p. $792-800$.

${ }^{7}$ Dei Verbum, n. 5.

${ }^{8}$ CONFERÊNCIA NACIONAL DOS BISPOS DO BRASIL, Catequese renovada, $\mathrm{n} .50$.

${ }^{9}$ Gaudium et Spes, n. 22, in: COMPÊNDIO DO VATICANO II, Constituições. Decretos. Declarações.

${ }^{10}$ Dei Verbum, n. 9. 
apóstolos que o Evangelho prometido antes pelos profetas e agora completado e promulgado por sua própria boca fosse por eles pregado a todos os homens como fonte de toda a verdade salvífica e de toda a disciplina de costumes, comunicandolhes dons divinos. Esta ordem foi fielmente executada tanto pelos apóstolos na pregação oral, por exemplos que receberam das palavras, da convivência e das obras de Cristo ou que aprenderam da "inspiração do Espírito Santo, quanto por aqueles apóstolos e varões apostólicos que, sob inspiração do mesmo Espírito Santo, puseram por escrito a mensagem da salvação."11

Assim, as coisas divinamente reveladas que se encerram por escrito e se manifestam na Sagrada Escritura sob a inspiração do Espírito Santo são tidas pela Santa Mãe Igreja, segundo a fé apostólica, como sagradas e canônicas. ${ }^{12}$ A Bíblia é um livro muito antigo. É o resultado por escrito de uma longa experiência entre o povo de Israel e Deus. Também é sinônimo de Sagradas Escrituras, pois foi inspirada por Deus.

\section{A Palavra de Deus e a catequese}

A catequese, pela sua própria natureza, insere-se no que é relativo ao ministério da Palavra. Este ministério é o que, desde os tempos apostólicos, se chama de diaconia (ou serviço) da Palavra. ${ }^{13}$ No exercício ministerial, a catequese atua ao lado de outros momentos do mesmo ministério: o anúncio missionário, a pregação litúrgica, a reflexão teológica etc. Essa atuação atinge o que se refere tanto aos acontecimentos quanto à mediação histórica.

\subsection{Catequese: serviço à Palavra e anúncio de Cristo}

No centro da catequese está a necessidade da integração entre fé e vida. $\mathrm{O}$ anúncio da Palavra se faz a partir das situações e dos problemas da vida. Nasce, assim, a necessidade de que a catequese se encarne verdadeiramente nas diversas culturas, pois, se a Palavra de Deus se encarna na história dos homens, é necessário esclarecer em que sentido e condições essa Palavra pode relacionar-se com as diferentes culturas. ${ }^{14}$

\footnotetext{
${ }^{11}$ Dei Verbum, n. 7.

${ }^{12}$ Dei Verbum, n. 11.

${ }^{13}$ ALBERICH, Catequese evangelizadora, p. 90.

${ }^{14}$ ALBERICH, Catequese evangelizadora, p. 103-105.
} 
A Palavra de Deus revelada em Jesus Cristo deve estar no coração da catequese. Nesse aspecto, a Constituição Dei Verbum, do Vaticano II, é um documento importante, pois ressalta uma visão mais existencial e pessoal, mais cristológica e aberta à história. Na mesma perspectiva, o Diretório Nacional de Catequese destaca que

o conjunto realizado por Deus ao longo da História da Salvação, com as obras e mensagens dos profetas, é Revelação de Deus, que em Jesus Cristo, em sua vida e palavra, não só alcança o mais elevado grau, mas se constitui no critério absoluto de interpretação da história salvífica anterior. "Os apóstolos, transmitindo aquilo que eles próprios receberam, exortam os fiéis a manter as tradições que aprenderam, seja oralmente, seja por carta (cf. 2Ts 2,15), e a combater pela fé que se lhes transmitiu uma vez para sempre (Jd 3)" (DV 8,1). A pregação apostólica é "expressa de um modo especial nos livros inspirados" (DV 8). ${ }^{15}$

De fato, a catequese, como serviço à palavra, deve proporcionar a cada indivíduo, através dos ensinamentos da Sagrada Tradição e da aproximação ao Evangelho de Jesus nas Sagradas Escrituras, uma experiência pessoal com o Cristo, que é a plenitude da Revelação de Deus aos homens. Nessa perspectiva, pode-se afirmar que a Palavra de Deus é fundamento da catequese.

\subsection{Catequese: processo de evangelização}

A catequese é um dos meios pelos quais Deus continua hoje a se manifestar às pessoas. Ela atualiza a Revelação acontecida no passado. Porém, a evangelização do mundo é um desafio para a Igreja: "Nossa realidade pede uma nova evangelização. A catequese coloca-se dentro dessa perspectiva evangelizadora, mostrando uma grande paixão pelo anúncio do Evangelho". ${ }^{16}$

\subsubsection{Primeiro anúncio e catequese}

É vocação da Igreja anunciar a Boa Notícia do Reino proclamado e realizado por Jesus Cristo. O centro do primeiro anúncio é a pessoa de Jesus, proclamando o Reino como uma nova e definitiva intervenção de Deus. Ao transmitir a mensagem

${ }^{15}$ CONFERÊNCIA NACIONAL DOS BISPOS DO BRASIL. Diretório Nacional de Catequese. São Paulo: Paulinas, 2006. n. 23.

${ }^{16}$ CONFERÊNCIA NACIONAL DOS BISPOS DO BRASIL, Diretório Nacional de Catequese, n. 29. 
do Reino, a catequese a desenvolve, aprofunda e mostra suas repercussões para as pessoas e para o mundo. O Diretório Nacional de Catequese, em seu número 31, explicita o primeiro anúncio querigmático sublinhando alguns elementos que desembocam em uma catequese totalmente cristocêntrica.

Nessa dimensão cristocêntrica e pessoal da Palavra de Deus, o autor Emílio Alberich enfatiza que o testemunho bíblico, por meio dos títulos messiânicos (Messias, Cristo, Filho de Deus, Senhor, Salvador etc.) e mesmo através de outras denominações que procuram evidenciar o alcance existencial para nós (caminho, verdade e vida, luz, água, bom pastor, sabedoria de Deus etc.), reafirma de muitos modos a certeza de que, em Jesus de Nazaré, aconteceu algo de decisivo para a humanidade, de que nele o ser humano encontra a chave para a interpretação da vida e a garantia de um projeto renovado de humanidade. Ainda mais: que o encontro com Jesus se torna, portanto, o sacramento por excelência do encontro do ser humano com Deus, ao mesmo tempo em que manifesta a intenção personalista da Revelação. ${ }^{17}$

De fato, "a catequese é acima de tudo anúncio de Cristo. Jesus Cristo, na plenitude de sua pessoa e de seu ministério, é o centro indiscutível da comunicação catequética e ponto de referência de todo o seu conteúdo". ${ }^{18}$ Com base no Diretório Geral de Catequese, pode-se afirmar que Jesus Cristo é o verdadeiro sujeito agente da catequese.

\section{A Bíblia como livro por excelência da catequese}

A princípio, a Revelação de Deus foi conservada pela tradição oral, contada de pai para filho (Dt 4,10; 11,19). Depois, sob a inspiração do Espírito Santo, foi posta por escrito na Bíblia: "A Bíblia usa raramente a palavra 'Revelação'. Tampouco faz teorias sobre ela. Conta, sobretudo, fatos. Alguns desses fatos podem ajudar-nos a compreender como se dá a Revelação. Principalmente fatos que apresentam o encontro de Deus com seu povo". ${ }^{19}$ Assim, ao reconhecer que a Bíblia é a Palavra de Deus redigida sob a moção do Espírito Santo e que com a Sagrada Tradição, constitui um único deposito da fé, e ao considerar a dimensão e os objetivos da catequese, é possível afirmar que a Bíblia é o livro por excelência da catequese.

\footnotetext{
${ }^{17}$ ALBERICH, Catequese evangelizadora, p. 108-109.

${ }^{18}$ ALBERICH, Catequese evangelizadora, p. 110.

${ }^{19}$ CONFERÊNCIA NACIONAL DOS BISPOS DO BRASIL, Catequese renovada, n. 46.
} 
O uso da Bíblia na catequese deve estar a serviço de uma fé esclarecida e engajada. Tem como objetivo formar a comunidade de fé e alimentar a comunidade cristã. Denota-se, por primeiro, como a organização de um grupo de pessoas para a reflexão dos textos bíblicos é capaz de formar verdadeiras comunidades. Estas podem mais facilmente buscar a vontade de Deus, crescendo assim na fé. Em segundo lugar, é necessário que os cristãos busquem nos ensinamentos da Bíblia a sua verdadeira identidade. Alimentando-se da Palavra de Deus nela contida, ajudam a formar a Igreja. Contudo, é indispensável proporcionar uma leitura que seja capaz de relacionar o texto com o contexto e com o cotidiano da vida. Contudo, esse processo não é tão simples, pois a mesma Bíblia é lida por movimentos de diversas tendências, os quais, muitas vezes, chegam a resultados diferentes e até opostos. ${ }^{20}$

\section{Conclusão}

A relação da Palavra de Deus com a Bíblia e com a catequese favorece a conexão das duas últimas. Deve-se destacar a Palavra de Deus como fonte de toda a Revelação que culmina na pessoa de Jesus Cristo.

A catequese apresentada como ministério da Palavra de Deus deve ter presente que a pessoa de Jesus Cristo é o centro do seu processo de evangelização. Nessa perspectiva, a catequese, por sua natureza e dimensão cristocêntrica, tem a missão de conduzir a um encontro pessoal com o próprio Cristo, que é a Palavra de Deus revelada. Desse modo, a Bíblia é o livro por excelência da catequese, pois o contato com a Sagrada Escritura favorece a compreensão do Cristo em toda a história da salvação. O acesso ao conhecimento bíblico na catequese favorece a compreensão da Revelação de Deus. Portanto, a catequese deve estar a serviço da fé comunitária cristã e alimentá-la, formando verdadeiras comunidades, por mais difícil que esse processo se mostre.

\section{Referências bibliográficas}

ALBERICH, Emílio. Catequese evangelizadora; manual de catequética fundamental. São Paulo: Salesiana, 2007.

\footnotetext{
${ }^{20}$ LIMA, Luiz Alves de. A face brasileira da catequese: um estudo histórico-pastoral do movimento catequético brasileiro das origens ao diretório "catequese renovada". Tese de doutorado n. 346. Roma: Universidade Pontifícia Salesiana, 1995. p. 409.
} 
- A catequese no contexto do Concílio Vaticano II e o pós-Concílio. Revista de catequese 61, 1993, p. 15-26.

BÍBLIA DE JERUSALÉM. 3. ed. São Paulo: Paulus, 2004.

COMPÊNDIO DO VATICANO II. Constituições. Decretos. Declarações. Petrópolis: Vozes, 1986.

CONFERÊNCIA NACIONAL DOS BISPOS DO BRASIL (CNBB). Diretório Nacional de Catequese. São Paulo: Paulinas, 2006. (Documentos da CNBB, 84).

. Catequese renovada; orientações e conteúdo. São Paulo: Paulinas, 1986. (Documentos da CNBB, 26).

EICHER, Peter. Dicionário de conceitos fundamentais de teologia. São Paulo: Paulus, 1993.

LIMA, Luiz Alves de. A face brasileira da catequese: um estudo históricopastoral do movimento catequético brasileiro das origens ao diretório "catequese renovada". Tese de doutorado n. 346. Roma: Universidade Pontifícia Salesiana, 1995.

PONTIFÍCIA COMISSÃO BÍBLICA. A interpretação da Bíblia na Igreja. São Paulo: Paulinas, 2004.

Fabiana de Sousa

Mestranda em Teologia Sistemática pela PUC-SP

São Paulo/SP - Brasil

E-mail: sousa-fabi@bol.com.br

Recebido em: 01/06/13

Aprovado em: 20/10/14 